\title{
The cardiac patient in Ramadan
}

Majed Chamsi-Pasha, Hassan Chamsi-Pasha ${ }^{1}$

Departments of Medicine and 'Cardiology, King Fahad Armed Forces Hospital, Jeddah, Saudi Arabia

\begin{tabular}{|c|}
\hline Access this article online \\
\hline Website: www.avicennajmed.com \\
\hline DOI: 10.4103/2231-0770.179547 \\
\hline Quick Response Code: \\
\hline
\end{tabular}

\section{ABSTRACT}

Ramadan is one of the five fundamental pillars of Islam. During this month, the majority of the 1.6 billion Muslims worldwide observe an absolute fast from dawn to sunset without any drink or food. Our review shows that the impact of fasting during Ramadan on patients with stable cardiac disease is minimal and does not lead to any increase in acute events. Most patients with the stable cardiac disease can fast safely. Most of the drug doses and their regimen are easily manageable during this month and may need not to be changed. Ramadan fasting is a healthy nonpharmacological means for improving cardiovascular risk factors. Most of the Muslims, who suffer from chronic diseases, insist on fasting Ramadan despite being exempted by religion. The Holy Quran specifically exempts the sick from fasting. This is particularly relevant if fasting worsens one's illness or delays recovery. Patients with unstable angina, recent myocardial infarction, uncontrolled hypertension, decompensated heart failure, recent cardiac intervention or cardiac surgery or any debilitating diseases should avoid fasting.

Key words: Cardiac, coronary artery disease, fasting, Ramadan, hypertension

\section{INTRODUCTION}

Ramadan, the $9^{\text {th }}$ month of the Islamic calendar, when Muslims fast during the daylight hours to learn patience, self-restraint, sacrifice, and, above all, God-consciousness. During Ramadan, healthy Muslims, in all over the world, abstain from eating, drinking, connubial relationships, and smoking from dawn till sunset. Ramadan follows the lunar calendar and hence the fasting month is brought forward by about 10 days each year. This brings about a change of the season of fasting month in addition to the length of the fasting time which may vary from 11 to $18 \mathrm{~h}$. During the Ramadan fast, Muslims eat two meals a day, one before dawn (Suhur meal) and the other shortly after sunset (Iftar meal). The change of dietary patterns and meal schedule is accompanied by changes in sleeping patterns. ${ }^{[1]}$ This change in life-style, in terms of obtaining the daily calorie intake via two meals with alteration of medication schedule or reduction in sleep duration, might affect patients with cardiovascular diseases (CVD). ${ }^{[2]}$ Muslims whose health is at risk are exempted from fasting. The Qur'an states that fasting during illness should be avoided.

Address for correspondence: Dr. Hassan Chamsi-Pasha, Department of Cardiology, King Fahad Armed Forces Hospital, P.O. Box 9862, Jeddah 21159, Saudi Arabia.

E-mail: drhcpasha@hotmail.com

\section{STABLE CARDIAC DISEASE}

Although more than a billion Muslims observe Ramadan fast the world over, there is still relatively a small number of studies on the effect of fasting Ramadan on CVD. Chamsi-Pasha and Ahmed ${ }^{[3]}$ recruited 86 outpatients with different kinds of CVD (46 [53\%] patients with coronary artery disease $[\mathrm{CAD}])$ and reported that 74 patients (86\%) succeeded in fasting the whole month of Ramadan, while $9(10.4 \%)$ missed the fasting for up to 7 days and $3(3.5 \%)$ could not fast. No significant changes observed in the New York Heart Association (NYHA) class in the study population during the fasting of Ramadan. They concluded that the majority of patients with stable cardiac disease in this cohort fasted without significant detrimental effects.

Al Suwaidi et al..$^{[4]}$ studied 465 stable cardiac patients attending outpatient cardiology clinics with different

This is an open access article distributed under the terms of the Creative Commons Attribution-NonCommercial-ShareAlike 3.0 License, which allows others to remix, tweak, and build upon the work non-commercially, as long as the author is credited and the new creations are licensed under the identical terms.

For reprints contact: reprints@ medknow.com

Cite this article as: Chamsi-Pasha M, Chamsi-Pasha H. The cardiac patient in Ramadan. Avicenna J Med 2016;6:33-8. 
stable heart diseases including heart failure, atrial fibrillation (AF), and valvular disease who observed Ramadan fast (288 patients [62\%] had angina). They found that $91.2 \%$ fasted without detrimental effects, and only $6.7 \%$ felt worse during Ramadan fast. Of the studied subjects, $82.8 \%$ were compliant with cardiac medications and $68.8 \%$ were compliant with dietary instructions. Only 19 patients needed hospitalization during Ramadan for cardiac reasons. They concluded that the effects of fasting on patients with the stable cardiac disease are minimal, and most of these patients can fast.

Khafaji et al ${ }^{[5]}$ reported no adverse effects on the clinical status of stable cardiac patients while fasting during Ramadan. They studied 56 patients with different stable cardiac illnesses and reported that the heart condition has not deteriorated in any of the patients. They found that $71.4 \%$ of the patients had no change in their symptoms during fasting, whereas $28.6 \%$ felt better.

In a recent review of the MEDLINE literature published between January 1980 and September 2012, Salim et al. ${ }^{[2]}$ concluded that the effects of fasting Ramadan on patients with stable cardiac disease were minimal, and such patients were able to fast, provided they complied with the recommended medication regimens and dietary advice. $^{[2]}$

More recently, Mousavi et al. ${ }^{[6]}$ prospectively studied 148 patients with documented CAD and normal ejection fraction. They found that patients with CAD were able to observe Ramadan fast safely, and their symptoms were not significantly different from that of the nonfasting ones. In their study, none of the patients with a history of revascularization (percutaneous coronary intervention or coronary artery bypass grafting), who had no history of postrevascularization typical chest pain reported chest pain during the month of Ramadan. They concluded that patients with CAD and normal left ventricular function could fast during Ramadan.

\section{DO ACUTE CARDIAC EVENTS INCREASE IN RAMADAN?}

Several studies investigated whether Ramadan fasting has a negative effect on the incidence of admission with acute coronary syndromes (ACS) such as acute myocardial infarction (AMI) and unstable angina (UA). ${ }^{[2,7,8]}$

Ramadan fasting does not seem to increase the burden of acute cardiac illness. The incidence of acute coronary artery syndrome, acute decompensated heart failure, AF, and stroke is similar during the month of Ramadan when compared to the other nonfasting months. ${ }^{[2]}$ Temizhan et al. ${ }^{[7]}$ investigated the effects of Ramadan fasting on CAD patients. They compared the frequency of acute cardiac events (AMI and UA) during Ramadan with the figures one month before and after Ramadan on 1655 patients, treated in their hospital between 1991 and 1997. During the study period, the number of cases with ACS was significantly lower in Ramadan than before or after Ramadan. They concluded that Ramadan fasting does not increase ACS events. However, their study had several limitations; it was not a population-based study, and only included a small number of patients. ${ }^{[7]}$

Al Suwaidi et al ${ }^{[8]}$ used a database of all patients admitted to a Cardiology Department in Qatar where over 95\% of Qatari adults regularly practice fasting. All patients presenting with ACS were identified. Over a period of 10 years (1991-2001), a total of 20,856 patients were admitted of whom 8446 were Qataris. There was no significant difference in the incidence of AMI or UA before, during or after Ramadan. Pekdemir et al. ${ }^{[9]}$ found that the number of admissions with specific complaints to the Emergency Department did not change significantly during Ramadan as opposed to the 30-day period immediately after Ramadan.

\section{CONGESTIVE HEART FAILURE}

Fasting during Ramadan does not seem to increase hospitalizations for congestive heart failure (CHF). Al Suwaidi et al. ${ }^{[10]}$ investigated whether Ramadan fasting has any effect on the number of hospitalization for CHF using the same database described earlier. Overall, 2160 Qatari patients were hospitalized with CHF. Hospitalizations with CHF were not significantly different in the months before, during, or after Ramadan. There were no significant changes in the NYHA class $(P=0.12)$ nor in any of the hematological or biochemical parameters during Ramadan fasting. ${ }^{[10]}$ Nevertheless, patients with decompensated heart failure or those requiring large doses of diuretics are strongly advised not to fast, particularly when Ramadan falls during the summer.

The conclusions derived from these studies may not be extrapolated to patients with worse functional classes or those who are clinically unstable. It is noteworthy that most of these studies were carried out in the Middle East or Gulf area, and, therefore, such conclusions may not be entirely applicable to patients living in American or European countries, where the duration of daily fasting could be $2-3 \mathrm{~h}$ longer. ${ }^{[11]}$ 


\section{HYPERTENSION}

Many factors may theoretically influence the blood pressure (BP) during Ramadan. These include feeding patterns, sleep changes, and changes in the timing of intake of medication. Habbal et al..$^{[12]}$ studied the consequences of Ramadan fasting on variations of BP in 99 hypertensive patients over the course of $24 \mathrm{~h}$. All patients had an ambulatory BP measurement (ABPM) before the fast and during Ramadan. No statistically significant differences were noted between these two periods regarding systolic $\mathrm{BP}$ (SBP), diastolic BP, throughout the $24 \mathrm{~h}$ period.

Perk et al.$^{[13]}$ investigated the effects of fasting on 17 treated hypertensive patients. An ABPM was performed twice: Before Ramadan and during the last week of Ramadan. All patients continued their medications, which were given once-daily. They found no difference between the mean BP (MBP) before or during Ramadan. This was confirmed by a Ural et al. ${ }^{[14]}$ in their study of subjects with Grade 2-3 hypertension (HTN) using combination therapy. Twenty-four hours ABPM was performed during and after Ramadan. No statistically significant difference was found between the $24 \mathrm{~h}$ MBP in the two periods. ${ }^{[14]}$ In a small study of 65 healthy subjects, Shehab et al. found that SBP was significantly lower during Ramadan than either before or after.

These studies concluded that, in patients with uncomplicated essential HTN, Ramadan fasting was well tolerated. The variations of $\mathrm{BP}$ are minimal and are probably related to the changes in activity, sleep, and eating patterns. Patients with controlled HTN can safely fast Ramadan provided they adhere to their medications.

Based on these observations, recommendations were made on the management of HTN during Ramadan by two professional bodies in the Arabian Gulf region. ${ }^{[15,16]}$ They include that: (1) Physician's advice and management should be individualized. (2) Patients should seek medical advice before Ramadan so that their clinical status is assessed and medications can be adjusted. (3) Education should emphasize the adherence to both nonpharmacological and pharmacological measures. (4) Diuretics are better avoided, particularly in hot weather or to be taken in the early evening. (5) A once-daily medication with long-acting preparations is recommended. (6) Patients should be advised to take a low-salt, low-fat diet. (7) Patients with difficult to control HTN, are advised not to fast until their BP is controlled and (8) Patients with hypertensive emergencies should be treated appropriately regardless of fasting. ${ }^{[17]}$

\section{MEDICATIONS IN RAMADAN}

Patients are encouraged to seek medical advice 1 or 2 months before Ramadan to adjust their medications if needed. Drugs given thrice daily can be usually changed to single sustained release formulations. Dehydration and electrolyte imbalance that is often encountered with diuretics should be avoided particularly in cardiac patients where this can lead to serious cardiac dysrhythmias. Diuretics are not the first choice as a new antihypertensive for a fasting patient. Diuretics dosing, whether for the purpose of CHF or as antihypertensive, may need to be adjusted down during fasting, especially loop diuretics with prolonged fasting during hot seasons. Most cardiac medications have once-daily dosing that is highly recommended. ${ }^{[17,18]}$

\section{Warfarin and Ramadan fasting}

Ramadan fasting does not appear to influence adversely the efficacy or safety of oral anticoagulation. Saour et al. ${ }^{[19]}$ reported the first study (although not listed in MEDLINE) addressing the effects of fasting on warfarin therapy. Over a 5 -year period, they studied 289 patients. While on treatment, 106 patients fasted 309 Ramadan months (fasting group), and 183 patients elected not to fast during Ramadan (nonfasting group). Thromboembolic events occurred in two (1.88\%) and four patients $(2.18 \%)$ of the fasting and nonfasting groups, respectively. The authors concluded that Ramadan fasting does not adversely affect the efficacy and safety of oral anticoagulation. ${ }^{[19,20]}$

\section{RAMADAN FASTING AND SICK PATIENTS}

Fasting does not apply to all adult Muslims. If it is considered detrimental to an individual's health, the Qur'an states fasting should be avoided. "Allah intends every facility for you; he does not want to put you to difficulties."[21] This exemption represents more than a simple permission not to fast; the Prophet Muhammad said, "God likes his permission to be fulfilled, as he likes his will to be executed." ${ }^{[22]}$ A fundamental Islamic doctrine states: Hardship brings Ease. Fasting that exposes health to possible hazards is not in accordance with Islamic jurisprudence. Medical checkup 1 month before Ramadan is warranted, particularly for those with chronic illnesses such as CVD, diabetes mellitus, and renal disease. The decision whether the patient can fast or not is left to the discretion of the treating physician. ${ }^{[1]}$

\section{RISK FACTORS}

Fasting Ramadan is a radical change in life-style for the period of a lunar month, and life-style change has a significant impact on the cardiovascular system. 
Although not ostensibly, mentioned in the Qur'an and prophetic traditions, the life-style that the Qur'an advocates drastically decrease the chances of individuals developing the cardiovascular disease by the following ways: Moderate eating, physical exercise, engaging in spiritual activities, and abstention from forbidden foods and drinks. ${ }^{[23]}$ Overeating is strongly condemned and prohibited in the Qur'an. "Eat and drink, but be not excessive. Indeed, he does not like those who commit excess."[24]

Weight loss occurs during Ramadan fasting, and if maintained can be beneficial to patients, so they should be encouraged to preserve it, particularly if the patient suffers from metabolic syndrome, HTN, diabetes, and obesity. Smokers should be encouraged to stop smoking.

Nematy et al. ${ }^{[25]}$ reported a significant improvement in 10 years CAD risk factors based on Framingham risk score after Ramadan fasting. There were a significant higher high-density lipoprotein cholesterol (HDL-C) and lower low-density lipoprotein cholesterol (LDL-C), SBP, body mass index, and waist circumference after Ramadan. All these factors could be beneficial for the cardiovascular system.

Endothelial dysfunction, which can be manifested by loss of nitric oxide bioavailability, is an increasingly recognized cause of CVD. Studies showed that diets affect endothelial function and may modify cardiovascular risk. In a small study of 21 male patients with cardiovascular risks, Yousefi et al. ${ }^{[26]}$ reported that nitric oxide levels were significantly higher after Ramadan fasting compared with the baseline value. Further studies are warranted. ${ }^{[26]}$

\section{Lipids}

There is still some controversy about the effects of Ramadan fasting on lipid profile. In a study of 32 healthy male volunteers, Adlouni et al. ${ }^{[27]}$ reported that fasting Ramadan led to a significant decrease in serum total cholesterol (7.9\%), triglyceride (TG) (30\%) and LDL-C (11.7\%), with a significant increase in the serum HDL-C (14.3\%). Shehab et al. ${ }^{[28]}$ determined the effect of fasting during Ramadan on plasma lipid and lipoprotein variables among 65 healthy subjects. The authors found significant changes in TGs, HDL-C and LDL-C, at the end of Ramadan. Furthermore, there was a progressive and significant increase in HDL-C and decrease LDL-C, a month after Ramadan.

More recently, Kul et al. ${ }^{[29]}$ conducted a meta-analysis of 30 studies including 1476 healthy subjects and compared body weight, blood levels of lipids and fasting blood glucose before and after Ramadan. They had variable numbers of subjects and studies for each parameter. The primary findings of their study were that after Ramadan fasting LDL-C and fasting blood glucose levels were decreased in both genders compared to levels before Ramadan. In the female subgroup, body weight, total cholesterol and TG levels remained unchanged, while HDL-C level has increased. In male subjects, Ramadan fasting resulted in weight loss, reduction in total cholesterol and LDL-C levels and a small decrease in TG levels. The findings of this meta-analysis show that Ramadan fasting has some positive effects on some health outcomes in a healthy Muslim population, particularly among men. However, one should consider limitations of this study while interpreting the results. ${ }^{[29]}$

\section{Weight}

During the Ramadan fasting, there is a change in the number, timing, and calorie content of meals. In Ramadan, the number of meals is reduced to two, but the quantity and calorie content of each meal increase and this may contribute to a greater than expected calorie consumption. ${ }^{[30,31]}$

Reports about weight change during Ramadan are mixed. Various authors have reported weight loss, ${ }^{[32]}$ weight gain ${ }^{[33]}$ and no change in weight. ${ }^{[34]}$ These differences may, in part, be due to different ethnicities, age, gender, calorie intake, physical activity, and place of the study participants. However, the most consistent observation has been weight loss. In a meta-analysis by Sadeghirad et al. ${ }^{[32]}$ based on 35 studies, the mean reported weight loss over the 1 month period was $1.24 \mathrm{~kg}$.

On the contrary, El Ati et al.$^{[35]}$ found that the body weight remained unchanged. Although the consumption of dietary carbohydrate decreased, the dietary protein was increased due to greater intake of animal protein. Bakhotmah ${ }^{[33]}$ used a predesigned questionnaire and interviewed 173 Saudi families. 59.5\% of the participants reported weight gain during Ramadan, which was attributed to consumption of high-calorie food and restricted physical activity. However, the latter two studies seem to be exceptions rather than the norm.

Despite the fact that most studies have reported significant weight loss during Ramadan, almost all of them reported a uniform weight regain after Ramadan as well. In a meta-analysis by Sadeghirad et al., ${ }^{[32]}$ weight loss did not persist, and weight was regained within 2 weeks after Ramadan. A similar weight regain has also been reported by Saedeghi et al. ${ }^{[34]}$ underlining the fact that weight loss during Ramadan is transient. A successful weight management requires a structured program targeted at therapeutic life-style changes. Such a program needs to be started at least 
1-2 months before Ramadan. People should be evaluated for the presence of cardiac diseases, diabetes, and HTN.

\section{Physical activity}

Physical activity is also markedly restricted during Ramadan, and this should be modified.

Exercise can be conveniently done after the evening meal or before the morning meal. Aerobic exercise such as walking or cycling is preferred, and must include the physical exertion involved in the prayers, especially the Tarawih prayers. The Islamic prayer is performed at least 5 times a day and consists of a series of movements involving standing, prostrating and sitting. When performing prayer, the Qur'an discourages lazily performing prayer as performed by the hypocrites; ${ }^{[36]}$ thus, a lethargic and careless approach to prayer neither obtains any spiritual nor physical benefit to the state of health. ${ }^{[11]}$

\section{Smoking}

Many public health authorities have used the start of Ramadan as a spur to encourage smoking cessation, ${ }^{[37]}$ using several lines of reasoning. Smokers can be motivated by the fact that if they abstain from smoking during the daytime, then they could easily abstain later as well.

Enforced abstinence from smoking during daylight will engender withdrawal for many regular smokers. With sustained abstinence, the withdrawal will subside, but not with continued smoking during darkness, so the period of Ramadan is uncomfortable for many smokers unless they become totally abstinent. ${ }^{[38]}$ To make a better use of the Ramadan fast to enhance cessation, one may encourage smoking reduction as an initial target. Most smokers do not want to stop imminently, but most report trying to reduce. There is good evidence that smoking reduction programs enhance cessation. Muslim smokers should be encouraged to continue the method of controlling their smoking after the fast is broken. ${ }^{[38]}$

\section{CONCLUSION}

Patients with stable CAD can observe the fasting of Ramadan without anticipating any major adverse cardiac events while those with unstable disease or recent/pending revascularization should largely refrain. The incidence of AMI is not increased during Ramadan, and there was no increase in hospitalization with heart failure. Most cardiac medications can be prescribed once or twice daily.

A fairly small group of patients with cardiac conditions should be advised to refrain from fasting during Ramadan.
These include patients with acute cardiac illnesses, AMI and ACS. Patients with uncontrolled HTN requiring multiple dosages during the daytime should be counseled against fasting. Patients with severe CHF requiring high doses of diuretics should refrain from fasting. Ramadan is an ideal platform to target year long life-style modification, to ensure that whatever health care benefits have been gained during this month, are perpetuated.

\section{Financial support and sponsorship}

Nil.

\section{Conflicts of interest}

There are no conflicts of interest.

\section{REFERENCES}

1. Norouzy A, Salehi M, Philippou E, Arabi H, Shiva F, Mehrnoosh S, et al. Effect of fasting in Ramadan on body composition and nutritional intake: A prospective study. J Hum Nutr Diet 2013;26 Suppl 1:97-104.

2. Salim I, Al Suwaidi J, Ghadban W, Alkilani H, Salam AM. Impact of religious Ramadan fasting on cardiovascular disease: A systematic review of the literature. Curr Med Res Opin 2013;29:343-54.

3. Chamsi-Pasha H, Ahmed WH. The effect of fasting in Ramadan on patients with heart disease. Saudi Med J 2004;25:47-51.

4. Al Suwaidi J, Zubaid M, Al-Mahmeed WA, Al-Rashdan I, Amin H, Bener A, et al. Impact of fasting in Ramadan in patients with cardiac disease. Saudi Med J 2005;26:1579-83.

5. Khafaji HA, Bener A, Osman M, Al Merri A, Al Suwaidi J. The impact of diurnal fasting during Ramadan on the lipid profile, hs-CRP, and serum leptin in stable cardiac patients. Vasc Health Risk Manag 2012;8:7-14.

6. Mousavi M, Mirkarimi S, Rahmani G, Hosseinzadeh E, Salahi N. Ramadan fast in patients with coronary artery disease. Iran Red Crescent Med J 2014;16:e7887.

7. Temizhan A, Dönderici O, Ouz D, Demirbas B. Is there any effect of Ramadan fasting on acute coronary heart disease events? Int J Cardiol 1999;70:149-53.

8. Al Suwaidi J, Bener A, Suliman A, Hajar R, Salam AM, Numan MT, et al. A population based study of Ramadan fasting and acute coronary syndromes. Heart 2004;90:695-6.

9. Pekdemir M, Ersel M, Yilmaz S, Uygun M. No significant alteration in admissions to emergency departments during Ramadan. J Emerg Med 2010;38:253-6.

10. Al Suwaidi J, Bener A, Hajar HA, Numan MT. Does hospitalization for congestive heart failure occur more frequently in Ramadan: A population-based study (1991-2001). Int J Cardiol 2004;96:217-21.

11. Chamsi-Pasha H. Islam and the cardiovascular patient - Pragmatism in practice. Br J Cardiol 2013;20:1-2.

12. Habbal R, Azzouzi L, Adnan K, Tahiri A, Chraibi N. Variations of blood pressure during the month of Ramadan. Arch Mal Coeur Vaiss 1998;91:995-8.

13. Perk G, Ghanem J, Aamar S, Ben-Ishay D, Bursztyn M. The effect of the fast of Ramadan on ambulatory blood pressure in treated hypertensives. J Hum Hypertens 2001;15:723-5.

14. Ural E, Kozdag G, Kilic T, Ural D, Sahin T, Celebi O, et al. The effect of Ramadan fasting on ambulatory blood pressure in hypertensive patients using combination drug therapy. J Hum Hypertens 2008;22:208-10.

15. Saudi Hypertension Management Group. Saudi hypertension management guidelines, 2007: Executive summary/Saudi Arabia. Riyadh: Saudi Hypertension Management Group; 2007. p. 26-7. 
16. Hypertension during Ramadan and Hajj. In: Guidelines for Management of Hypertension in Primary care Settings and Outpatient Clinics in the Kingdom of Bahrain. Bahrain: Ministry of Health, Health Promotion Council; 2008. p. 35-6.

17. Beshyah SA, Fathalla W, Saleh A, Al Kaddour A, Noshi M, Al Hateethi H, et al. Ramadan fasting and the medical patient: An overview for clinicians. Ibnosina J Med Biomed Sci 2010;2:240-57.

18. Khan IA. Coronary artery disease and diabetes - Management during Ramadan. J Pak Med Assoc 2015;65 5 Suppl 1:S62-4.

19. Saour JN, Sieck J, Khan M, Mammo L. Does Ramadan fasting complicate anticoagulation therapy? Ann Saudi Med 1989;9:538-40.

20. Skaik Y, Chamsi-Pasha H. The effects of fasting in Muslim patients taking warfarin: Comment. J Thromb Haemost 2014;12:807-8.

21. Al-Hilali MT, Khan MM. The Translation of the Meanings of the Noble Quran 2:185. Madina (KSA): King Fahd Complex for the Printing of the Holy Quran; 2005.

22. Al-Albani MN, Sahih Al Jamae. Hadith No: 1885. Dar Almaktab Alislami. Damascus, Syria. 2002.

23. Turgut O, Yalta K, Tandogan I. Islamic legacy of cardiology: Inspirations from the holy sources. Int J Cardiol 2010;145:496.

24. Al-Hilali MT, Khan MM. The Translation of the Meanings of the Noble Quran 7:31. Madina (KSA): King Fahd Complex for the Printing of the Holy Quran; 2005.

25. Nematy M, Alinezhad-Namaghi M, Rashed MM, Mozhdehifard M, Sajjadi SS, Akhlaghi S, et al. Effects of Ramadan fasting on cardiovascular risk factors: A prospective observational study. Nutr J 2012;11:69.

26. Yousefi B, Faghfoori Z, Samadi N, Karami H, Ahmadi Y, Badalzadeh R, et al. The effects of Ramadan fasting on endothelial function in patients with cardiovascular diseases. Eur J Clin Nutr 2014;68:835-9.

27. Adlouni A, Ghalim N, Benslimane A, Lecerf JM, Saile R. Fasting during Ramadan induces a marked increase in high-density lipoprotein cholesterol and decrease in low-density lipoprotein cholesterol. Ann Nutr Metab 1997;41:242-9.

28. Shehab A, Abdulle A, El Issa A, Al Suwaidi J, Nagelkerke N. Favorable changes in lipid profile: The effects of fasting after Ramadan. PLoS One 2012;7:e47615.

29. Kul S, Savas E, Öztürk ZA, Karadag G. Does Ramadan fasting alter body weight and blood lipids and fasting blood glucose in a healthy population? A meta-analysis. J Relig Health 2014;53:929-42.

30. Sethi BK, Nagesh VS. Weight management in Ramadan. J Pak Med Assoc 2015;65 5 Suppl 1:S54-6.

31. Meo SA, Hassan A. Physiological changes during fasting in Ramadan. J Pak Med Assoc 2015;65 5 Suppl 1:S6-14.

32. Sadeghirad B, Motaghipisheh S, Kolahdooz F, Zahedi MJ, Haghdoost AA. Islamic fasting and weight loss: A systematic review and meta-analysis. Public Health Nutr 2014;17:396-406.

33. Bakhotmah BA. The puzzle of self-reported weight gain in a month of fasting (Ramadan) among a cohort of Saudi families in Jeddah, Western Saudi Arabia. Nutr J 2011;10:84.

34. Saedeghi H, Omar-Fauzee MS, Jahromi MK, Abdullah MN, Rosli MH. The effects of Ramadan fasting on the body fat percent among adults. Ann Biol Res 2012;3:3958-61.

35. El Ati J, Beji C, Danguir J. Increased fat oxidation during Ramadan fasting in healthy women: An adaptative mechanism for body-weight maintenance. Am J Clin Nutr 1995;62:302-7.

36. Loukas M, Saad Y, Tubbs RS, Shoja MM. The heart and cardiovascular system in the Qur'an and Hadeeth. Int J Cardiol 2010;140:19-23.

37. Ghouri N, Atcha M, Sheikh A. Influence of Islam on smoking among Muslims. BMJ 2006;332:291-4.

38. Aveyard P, Begh R, Sheikh A, Amos A. Promoting smoking cessation through smoking reduction during Ramadan. Addiction 2011;106:1379-80. 